\title{
ANALISIS PRODUKSI DAN PENDAPATAN PETANI PADI SAWAH YANG MENGGUNAKAN PUPUK HAYATI CAIR DI DESA BLANG CUT KECAMATAN SUKA MAKMUR KABUPATEN ACEH BESAR
}

\author{
(Analysis Of Production And Revenues Of Paddy Farmers Who Use Liquide Bio- \\ Fertilizer In Village Blang Cut Subdistrict Suka Makmur District Aceh Besar)
}

\author{
Syukran$^{1}$, Ismayani ${ }^{1}$, Fajri Jakfar ${ }^{1 *}$ \\ ${ }^{1}$ Program Studi Agribisnis, Fakultas Pertanian, Universitas Syiah Kuala
}

\begin{abstract}
Abstrak. Hasil produksi padi sawah yang rendah diakibatkan oleh kerusakan tanah, kerusakan tanah disebabkan oleh penggunaan pupuk kimia secara terus - menerus. Produksi tersebut mengakibatkan menurunnya pendapatan petani padi sawah. Terdapat inovasi terbaru mengenai cara pemupukan untuk membantu penyuburan tanah. Salah satu inovasi tersebut adalah pupuk hayati cair, penggunaan pupuk hayati cair dapat menurunkan penggunaan pupuk kimia sehingga dapat menurunkan biaya pemupukan kimia. Pengimplementasian pupuk ini dapat meningkatkan hasil produksi padi sawah. Oleh karena itu penelitian ini bertujuan untuk melihat berapa besar penurunan biaya pemupukan kimia saat menggunakan pupuk hayati cair serta untuk mengetahui peningkatan pendapatan petani padi sawah setelah menggunakan pupuk hayati cair. Hasil penelitian menunjukkan bahwa dengan menggunakan pupuk hayati cair dapat menekan biaya pemupukan kimia serta dapat meningkatkan hasil produksi padi dan pendapatan petani padi sawah.
\end{abstract}

Kata kunci: pupuk hayati cair, produksi padi, pendaptan petani.

Abstract. Low production of paddy caused by defective soil. Devective soil caused by using chemical fertilizer continously. Low production of paddy caused decreasing income of paddy farmers. There was innovation about how to aid and fertilize the defective soil. One of the innovation is liquid bio-fertilizer. Application of liquid bio-fertilizers could provide less using chemical fertilizers. With the result that reduce chemical fertilizer oprational cost. Liquid bio-fertilizer not only fixing contexture of soil but also increasing production of paddy. Hence, this research purpose to show the magnitude of reducing chemical fertilizer oprasional costs along with using liquid biofertilizer and to find out the increasing of paddy farmers income afterwards. The result showed that by using liquid bio-fertilizer had reduced the cost of using chemical fertilizers, increased production, and increasing the income of paddy farmers.

Keywords: Bio-fertilizers, rice production, farmers income.

\section{PENDAHULUAN}

Penyebab rendahnya produksi di Aceh salah satunya adalah pemupukan kimia yang dilakukan secara terus menerus oleh petani padi sawah menyebabkan kondisi lahan menjadi kritis sehingga mempengaruhi produksi padi sawah. Rendahnya produksi petani padi sawah dapat mempengaruhi pendapatan petani.

Upaya untuk meningkatkan produksi pertanian di Indonesia salah satunya dengan intensifikasi yaitu dengan menerapkan formula pancausahatani yaitu salah satunya adalah penggunaan pupuk yang berimbang. kondisi lahan padi sawah kritis yang disebabkan karena penggunaan pupuk kimia secara terus - menerus dapat diatasi dengan pemberian pupuk yang dapat menyuburkan tanah. Untuk itu, diperlukan upaya baru khususnya pada pemupukan pada usahatani padi sawah tanpa mengurangi hasil pertanian. 
Dalam era global sekarang ini banyak inovasi dan penelitian mengenai cara - cara pengguaan pupuk dan kombinasi pupuk. Kombinasi pupuk organik atau non organik dengan dosis tertentu agar tanah kritis dapat kembali seperti semula. Terdapat juga penggunaan pupuk hayati baik berupa pupuk hayati cair atau pupuk hayati padat yang dapat meningkatkan kesuburan tanah. Inovasi tentang pupuk hayati terbaru adalah penggunaan pupuk campuran antara pupuk hayati dengan pupuk organik dan pupuk kimia.

Permentan (2006), "menggolongkan pupuk hayati kedalam pembenah tanah, bukan pupuk organik. Pembenah tanah itu sendiri bisa organik ataupun non organik. Pupuk hayati termasuk dalam pembenah tanah organik yang mengandung sekumpulan organisme hidup yang aktivitasnya bisa memperbaiki kesuburan tanah." Selain itu juga pupuk hayati mengandung unsur hara yang dibutuhkan bagi tanaman.

Pupuk hayati cair biasanya dijual lebih tinggi dari pupuk organik biasa di toko - toko yang menjual bahan dan alat pertanian. Bahkan jenis pupuk yang berupa biang atau disebut juga agen hayati ini dijual dengan harga yang lebih mahal dibandingkan dengan pupuk kimia. Karena pupuk tersebut diperuntukkan sebagai biang, sehingga petani dapat memperbanyak pupuk hayati tersebut dengan proses perbanyakan organisme yang terdapat didalam kandungan pupuk hayati tersebut.

Tabel 1. Harga Pupuk Hayati Octabacter PT. Ambagiri

\begin{tabular}{|c|l|c|c|}
\hline No. & \multicolumn{1}{|c|}{ Nama } & Harga (Rp) & Volume (mL) \\
\hline 1 & Octabacter Dekomposer & 95.000 & 1000 \\
\hline 2 & Octabacter Panik & 95.000 & 1000 \\
\hline 3 & Octabakter POC & 95.000 & 1000 \\
\hline
\end{tabular}

Sumber: Hasil survei tahun 2016

Pupuk hayati dapat diaplikasikan pada tanah, daun, akar, batang pada tumbuhan. Pupuk ini biasanya efektif diterapkan pada tanah yang memiliki kandungan organik tinggi. Mikroorganisme yang terdapat didalamnya membutuhkan kondisi yang baik untuk tumbuh dan berkembang. Penggunaannya pada tanah yang miskin kandungan organik sebaiknya dikombinasikan dengan penggunaan pupuk kompos, pupuk hijau, pupuk kandang atau pupuk organik lainnya.

Saat ini, pupuk hayati dilihat dari kandungan mikroorganismenya dibagi menjadi dua jenis, yaitu pupuk dengan mikroorganisme tunggal dan mikroorganisme majemuk. Pupuk dengan mikroorganisme tunggal hanya mengandung satu jenis mikroba yang memiliki satu fungsi, semisal mikroba dari jenis Rhizobium sp sebagai penambat nitrogen. Sedangkan pupuk dengan mikroorganisme majemuk biasanya memiliki lebih dari tiga jenis mikroba.

Petani sulit menerima inovasi penggunaan pupuk hayati cair karena tidak banyak petani yang menggunakan pupuk hayati cair sebagai input dalam usahataninya dan petani di daerah penelitian masih sangat bergantung pada pupuk kimia. Harga pupuk hayati yang mahal juga menjadi pertimbangan untuk menerapkan pupuk hayati ini karena mahalnya pupuk dapat meningkatkan biaya dalam usahatani namun dalam anggapan masyarakat belum tentu dapat meningkatkan produksi. Peningkatan produksi ini nantinya akan berdampak pada

Analisis Produksi dan Pendapatan Petani Padi Sawah yang Menggunakan Pupuk Hayati Cair di Desa Balang Cut Kecamatan Suka Makmur Kabupaten Aceh Besar. (Syukran, Ismayani, 272 Fajri Jakfar)

Jurnal Ilmiah Mahasiswa Pertanian Unsyiah, Vol. 2, No. 4, November 2017: 271-277 
peningkatan pendapatan petani atau tidak meningkatkannya pendapatan petani. Selain itu, petani belum banyak yang mengetahui tentang peningkatan produksi yang diperoleh jika penggunaan pupuk hayati cair dilakukan pada proses usahataninya.

Peneliti melakukan analisis biaya dan dampak penggunaan pupuk hayati cair terhadap pendapatan petani dari usahatani padi sawah yang menggunakan pupuk hayati cair sehingga penggunaan pupuk ini dapat dianjurkan untuk meningkatkan pendapatan petani padi sawah di Aceh pada masa yang akan datang.

Tujuan dari penelitian ini adalah 1) Mengetahui berapa besar pengurangan biaya pupuk kimia padi pada usahatani padi sawah yang menggunakan pupuk hayati cair di Desa Blang Cut Kecamatan Suka Makmur Kabupaten Aceh Besar. 2) Mengetahui berapa produksi dan berapa pendapatan petani padi sawah yang menggunakan menggunakan pupuk hayati cair di Desa Blang Cut Kecamatan Suka Makmur Kabupaten Aceh Besar.

\section{METODE PENELITIAN}

Penelitian ini dilakukan di Kecamatan Darussalam Kabupaten Aceh Besar. Penentuan lokasi penelitian ini ditentukan secara sengaja (Purposive) dengan pertimbangan bahwa daerah penelitian tersebut merupakan daerah yang memiliki petani yang menggunakan pupuk hayati cair di Desa Balng Cut Kecamatan Suka Makmur Kabupaten Aceh Besar. Penelitian ini telah dilaksanakan pada bulan Agustus 2016. Objek dari penelitian ini adalah petani padi sawah yang menggunakan pupuk hayati cair. Ruang lingkup dari penelitian ini terbatas pada analisis produksi dan pendapatan usahatani padi sawah di Desa Blang Cut Kecamatan Suka Makmur Kabupaten Aceh Besar.

Jenis data yang digunakan dalam penelitian ini, yaitu data primer berupa karakterisrik petani responden, teknik budidaya, luas lahan, sarana produksi, tenaga kerja, biaya produksi dan produksi dan nilai produksi, pendaptan petani. sedangkan data sekunder berupa data produksi padi di daeerah penelitian sebelum menggunakan pupuk hayati cair. Data primer diperoleh dari pengamatan dan wawancara langsung dengan responden, sedangkan data sekunder digunakan untuk mendukung data primer yang diperoleh dari lembaga, instansi, buku, jurnal dan laporan yang berhubungan dengan penelitian.

Metode yang digunakan dalam penelitian ini adalah Metode Sensus. Metode pengambilan sampel dilakukan secara sengaja (Purposive Sampling) dengan alasan sifat populasi di daerah penelitian relatif homogen. Jumlah sampel yang di ambil adalah 7 orang petani sampel yang menggunakan pupuk hayati cair. Metode analisis menggunakan rumus pendapatan

\section{Analisis Pendapatan}

analisis pendapatan bertujuan untuk menganalisis pendapatan usahatani padi sawah yang menggunakan pupuk hayati cair di Desa Blang Cut Kecamatan Suka Makmur Kabupaten Aceh Besar dengan menggunakan rumus berikut.

Biaya total, yaitu biaya keseluruhan dari jumlah biaya produksi yang telah dikeluarkan dengan cara menjumlahkan biaya tetap dan biaya tidak tetap.

Analisis Produksi dan Pendapatan Petani Padi Sawah yang Menggunakan Pupuk Hayati Cair di Desa Balang Cut Kecamatan Suka Makmur Kabupaten Aceh Besar. (Syukran, Ismayani, 273 Fajri Jakfar)

Jurnal Ilmiah Mahasiswa Pertanian Unsyiah, Vol. 2, No. 4, November 2017: 271-277 
$\mathrm{TC}=\mathrm{FC}+\mathrm{VC}$

(Dumairy, 2004)

Keterangan:

TC : Total Cost $(\mathrm{Rp} / \mathrm{MT})$

FC : Fixed Cost (Rp/MT)

VC : Variabel Cost (Rp/MT)

Total revenue (total penerimaan) dapat dihitung dengan menggunakan rumus:

$\mathrm{TR}=\mathrm{P}$ X Q

(Dumairy, 2004)

Keterangan:

TR : Total Revenue (Rp/MT)

$\mathrm{P} \quad$ : Harga $(\mathrm{Rp} / \mathrm{Kg})$

Q : Jumlah Unit Produksi (Kg/MT)

Untuk mengetahui pendapatan pada usahatani sayur-sayuran dilakukan dengan rumus sebagai berikut:

$\pi=\mathrm{TR}-\mathrm{TC}$ (Soehoroe, 1994)

Keterangan:

$\pi \quad$ : Pendapatan Usahatani Sayur-sayuran (Rp/MT)

TR : Total Revenue (Rp/MT)

TC : Total Cost (Rp/MT)

\section{HASIL PENELITIAN DAN PEMBAHASAN}

\section{Analisis Biaya Pemupukan kimia Sebelum dan sesudah penggunaanpupuk hayati cair}

Hasil penelitian yang menunjukkan penggunaan pupuk kimia sebelum dan sesudah menggunakan pupuk hayati cair dapat dilihat pada tabel 2 berikut ini.

Tabel 2. Rata - Rata jumlah pupuk kimia yang dikeluarkan petani dan total biaya rata - rata pupuk sebelum penggunaan dan setelah penggunaan pupuk hayati cair.

\begin{tabular}{|c|c|c|c|c|c|c|c|c|}
\hline \multirow[b]{2}{*}{ No. } & \multirow{2}{*}{$\begin{array}{r}\text { Jenis } \\
\text { Pupuk }\end{array}$} & \multicolumn{3}{|c|}{ Sebelum } & \multicolumn{3}{|c|}{ Sesudah } & \multirow[b]{2}{*}{$\begin{array}{c}\text { Perubahan } \\
(\%)\end{array}$} \\
\hline & & $\begin{array}{c}\text { Jumlah } \\
(\mathrm{Kg})\end{array}$ & $\begin{array}{c}\text { Harga } \\
(\mathrm{Rp})\end{array}$ & $\begin{array}{l}\text { Total } \\
(\mathrm{Rp})\end{array}$ & $\begin{array}{c}\text { Jumlah } \\
(\mathrm{Kg})\end{array}$ & $\begin{array}{c}\text { Harga } \\
(\mathrm{Rp})\end{array}$ & $\begin{array}{l}\text { Total } \\
(\mathrm{Rp})\end{array}$ & \\
\hline 1 & Urea & 53 & 2.200 & 116.600 & 18,7 & 2.200 & 41.140 & 64,7 \\
\hline 2 & $S P-36$ & 36 & 2.400 & 86.400 & 27,3 & 2.400 & 65.520 & 24,1 \\
\hline 3 & NPK & 14 & 2.600 & 36.400 & 11 & 2.600 & 28.600 & 21,4 \\
\hline \multicolumn{2}{|c|}{ TOTAL } & & & 239.400 & & & 135.260 & 43,4 \\
\hline
\end{tabular}

Sumber: Data Primer (diolah), 2016

Berdasarkan tabel 2 diatas dapat dilihat bahwa penggunaan pupuk kimia dapat diturunkan dengan menggunakan pupuk hayati cair dan biaya yang dikeluarkan untuk pupuk kimia lebih kecil setelah menggunakan pupuk hayati cair. berikut adalah penurunan jumlah pupuk yang dilakukan pada saat pemakaian pupuk hayati cair ; pupuk urea dapat diturunkan penggunaannya sebesar $64,7 \%$, pupuk SP - 36 dapat diturunkan penggunaannya sebesar 24,1\%, dan pupuk NPK dapat diturunkan penggunaannya sebesar $21,4 \%$. Biaya pupuk kimia rata - rata total yang

Analisis Produksi dan Pendapatan Petani Padi Sawah yang Menggunakan Pupuk Hayati Cair di Desa Balang Cut Kecamatan Suka Makmur Kabupaten Aceh Besar. (Syukran, Ismayani, 274 Fajri Jakfar)

Jurnal Ilmiah Mahasiswa Pertanian Unsyiah, Vol. 2, No. 4, November 2017: 271-277 
dikeluarkan petani padi sawah setelah penggunaan pupuk hayati cair adalah sebesar Rp 239.400,-/MT sedangkan biaya pupuk kimia rata - rata total yang dikeluarkan petani padi sawah sebelum penggunaan pupuk hayati cair adalah sebesar Rp 135.260,-/MT.

\section{Penggunaan Biaya Total Produksi Padi Sawah Sebelum dan Sesudah Menggunakan Pupuk Hayati Cair.}

Berikut ini adalah rata - rata total biaya produksi usahatani padi sawah pada daerah penelitan dapat dilihat pada tabel 3 berikut ini.

Tabel 3. Rata - Rata Biaya Total / Total Cost (TC) Produksi Pada Usahatani Padi Sawah yang Menggunakan Pupuk Hayati Cair di Desa Blang Cut Kecamatan Suka Makmur Kabupaten Aceh Besar.

\begin{tabular}{|r|l|c|r|r|}
\hline No. & Jenis Biaya & Peningkatan (\%) & \multicolumn{1}{|c|}{ Sesudah (Rp) } & Sebelum (Rp) \\
\hline \multicolumn{3}{|c|}{ A Biaya Tetap/ Total Fixed Cost ( TFC) } & 173.571 \\
\hline 1 & Peralatan & 0 & 173.571 & 35.714 \\
\hline \multicolumn{3}{|c|}{ B. Biaya Variabel/ Total Variable Cost ( TVC) } \\
\hline 1 & Benih & 0 & 35.714 & 240.086 \\
\hline 2 & Pupuk & 22,7 & 310.971 & 814.286 \\
\hline 3 & Tenaga Kerja & 9,5 & 900.000 & 1.263 .657 \\
\hline \multicolumn{2}{|c|}{ TOTAL } & 11 & 1.420 .256 & \\
\hline
\end{tabular}

Sumber: Data Primer (diolah), 2016

Berdasarkan tabel 3 menunjukkan bahwa rata-rata total biaya produksi dikeluarkan oleh petani di daerah penelitian sebelum menggunakan pupuk hayati cair adalah sebesar Rp 1.263.657/MT. sedangkan sesudah melakukan penambahan input berupa pupuk cair hayati adalah sebesar Rp. 1.420.256/ MT.

\section{Produksi dan Nilai Produksi}

Berikut ini adalah produksi dan nilai produksi. Produksi, harga jual, dan nilai produksi petani padi sawah saat menggunakan pupuk hayati cair dan saat sebelum menggunakan pupuk hayati cair dapat dilihat pada tabel 4 berikut ini.

Tabel 4. Rata - Rata Produksi dan Nilai Produksi Padi Sesudah dan Sebelum Menggunakan Pupuk Hayati Cair di Desa Blang Cut Kecamatan Suka Makmur Kabupaten Aceh Besar

\begin{tabular}{|c|l|c|r|r|c|}
\hline No. & Uraian & Satuan & Sesudah & Sebelum & Persentase perubahan (\%) \\
\hline 1 & Produksi & $\mathrm{Kg}$ & 743 & 557 & 25 \\
\hline 2 & Harga Jual & $\mathrm{Rp} / \mathrm{Kg}$ & 5000 & 5000 & 0 \\
\hline 3 & Nilai Produksi & $\mathrm{Rp}$ & 3.714 .286 & 2.785 .714 & 25 \\
\hline
\end{tabular}

Sumber: Data Primer (diolah), 2016

Berdasarkan tabel 4 menunjukkan bahwa rata-rata produksi padi sawah yang menggunakan pupuk hayati cair lebih besar $25 \%$ dibandingkan dengan usaha padi sawah yang tidak menggunakan pupuk hayati cair. rata - rata hasil produksi setelah menggunakan pupuk hayati cair adalah sebesar $743 \mathrm{Kg} / \mathrm{MT}$ dan sebelum menggunakan pupuk hayati cair sebesar $557 \mathrm{Kg} / \mathrm{MT}$. Harga jual gabah kering giling saat penelitian adalah $\mathrm{Rp} 5000 / \mathrm{Kg}$.

Pendapatan Usahatani Padi Sawah dengan Menggunakan Pupuk Hayati Cair

Analisis Produksi dan Pendapatan Petani Padi Sawah yang Menggunakan Pupuk Hayati Cair di Desa Balang Cut Kecamatan Suka Makmur Kabupaten Aceh Besar. (Syukran, Ismayani, 275 Fajri Jakfar)

Jurnal Ilmiah Mahasiswa Pertanian Unsyiah, Vol. 2, No. 4, November 2017: 271-277 
Untuk mengetahui besarnya pendapatan yang diperoleh petani responden pada usahatani padi sawah di daerah penelitian dapat dilihat pada tabel 5 berikut ini.

Tabel 5. Rata -rata Pendapatan $(\pi)$ Petani pada Usahatani Padi Sawah Sesudah dan

Sebelum Menggunakan Pupuk Hayati Cair di Desa Blang Cut Kecamatan Suka Makmur Kabupaten Aceh Besar.

\begin{tabular}{|c|l|c|c|c|}
\hline No. & \multicolumn{1}{|c|}{ Uraian } & Satuan & Sesudah & Sebelum \\
\hline 1 & Nilai Produksi (TR) & $\mathrm{Rp}$ & 3.714 .286 & 2.785 .714 \\
\hline 2 & Biaya Produksi (TC) & $\mathrm{Rp}$ & 1.420 .256 & 1.263 .657 \\
\hline 3 & Pendapatan $(\pi)$ & $\mathrm{Rp}$ & 2.294 .029 & 1.522 .057 \\
\hline
\end{tabular}

Sumber: Data Primer (diolah), 2016

Berdasarkan tabel 5 menunjukkan bahwa rata-rata pendapatan yang diterima oleh petani padi sawah yang menggunakan pupuk hayati cair di Desa Blang Cut Kecamatan Suka Makmur Kabupaten Aceh Besar adalah sebesar Rp 2.294.029,- I MT dan petani padi sawah sebelum menggunakan pupuk hayati cair adalah sebesar Rp 1.522.057,-/ MT. Dapat diketahui bahwa pendapatan petani menggunakan pupuk hayati cair lebih besar dibandingkan dengan pendapatan petani padi sebelum menggunakan pupuk hayati cair.

\section{SIMPULAN DAN SARAN}

Usahatani padi sawah yang menggunakan pupuk hayati cair dapar menurunkan penggunaan pupuk kimia tanpa mengurangi hasil produksi. Biaya pupuk kimia rata - rata total yang dikeluarkan petani padi sawah setelah penggunaan pupuk hayati cair adalah sebesar Rp 239.400,-/MT sedangkan biaya pupuk kimia rata - rata total yang dikeluarkan petani padi sawah sebelum penggunaan pupuk hayati cair adalah sebesar Rp 135.260,-/MT. Selain itu, penggunaan pupuk hayati cair juga dapat meningkatkan pendapatan.hasil penelitian menunjukkan rata-rata pendapatan yang diterima oleh petani padi sawah yang menggunakan pupuk hayati cair di Desa Blang Cut Kecamatan Suka Makmur Kabupaten Aceh Besar adalah sebesar Rp 2.294.029,- / MT dan petani padi sawah sebelum menggunakan pupuk hayati cair adalah sebesar Rp 1.522.057,-/ MT. Dapat diketahui bahwa pendapatan petani menggunakan pupuk hayati cair lebih besar dibandingkan dengan pendapatan petani padi sebelum menggunakan pupuk hayati cair.

Berdasarkan hasil penelitian, disarankan kepada petani untuk melanjutkan usahatani padi sawah tersebut dengan menggunakan pupuk hayati cair secara berkelanjutan. Dengan demikian petani dapat meningkatkan pendapatan dan menurunkan penggunaan pupuk kimia yang dapat merusak keadaan tanah.

\section{DAFTAR PUSTAKA}

Adiningsih, S. 1995. Ekonomi Mikro. BPFE. Yogyakarta

Amalia, R. 2015. Analisis Faktor-Faktor Produksi dan Pendapatan Usahatani Kacang Tanah Di Kecamatan Lembah Seulawah Kabupaten Aceh Besar (skripsi). Universitas Syiah Kuala. Banda Aceh.

Andriawan, I. 2010. Efektivitas Pupuk Hayati terhadap Pertumbuhan dan Hasil Padi Sawah (Oryza sativa L.) (Skripsi). Departemen Agronomi dan Hortikultura, Fakultas Pertanian. Institut Pertanian Bogor. Bogor.

Analisis Produksi dan Pendapatan Petani Padi Sawah yang Menggunakan Pupuk Hayati Cair di Desa Balang Cut Kecamatan Suka Makmur Kabupaten Aceh Besar. (Syukran, Ismayani, 276 Fajri Jakfar)

Jurnal Ilmiah Mahasiswa Pertanian Unsyiah, Vol. 2, No. 4, November 2017: 271-277 
Aulia, R. 2011. Analisis Pendapatan Usahatani Padi Sawah Dengan Penggunaan Pupuk Organik Di Desa Lambeugak Kecamatan Kuta Cot Glie Kabupaten Aceh Besar (Skripsi). Universitas Syiah Kuala. Banda Aceh.

BPS.2013. data statistik pertanian. Republik Indonesia.

BPS.2015. Aceh Besar Dalam Angka. Republik Indonesia

Departemen Pertanian, 2007. Rekomendasi Pemupukan N, P dan K pada Padi Sawah Spesifik Lokasi. Peraturan Menteri Pertanian Nomor 40/Permentan/OT. 140/04/2007. Departemen Pertanian, Jakarta.

Dumairy. 2004. Matematika Terapan Untuk Bisnis Dan Ekonomi. BPFE. Yogyakarta.

Gunawan, 2014. Penawaran kerja sama Produk Organik Cair PT. Ambagiri Nusantara. Banda Aceh.

Hernanto, F. 1993. Ilmu Usahatani. Penebar Swadaya. Jakarta. . 1988. Ilmu Usahatani, Jurusan Ilmu-Ilmu Sosial Ekonomi Pertanian. Fakultas Pertanian Institut Pertanian Bogor. Bogor.

Mubyarto. 1998. Pengantar Ekonomi Pertanian. LP3ES. Jakarta.

Nazir, M. 2003. Metode Penelitian. Ghalia Indonesia. Jakarta.

Partadiredja, A. 1990. Pengantar Ekonomika. BPFE. Yogyakarta

Rauf, AW dkk. 2000. Peranan Pupuk NPK Pada Tanaman Padi. jurnal : No. O 1/LPTP/IRJA199-00 Departemen pertanian badan penelitian dan pengembangan pertanian. Jaya Pura.

Republik Indonesia. 2006. peraturan kementerian pertanian. Sekretariat negara. Jakarta.

Purba, R . Kajian Pupuk Hayati pada Tanaman Padi Sawah di Banten. Jurnal Volume 1, Nomor 6, September 2015 : ISSN: 2407-8050. Balai pengkajian Teknologi Pertanian ( BPTP). Banten.

Riyanto, B. 1994. Dasar-Dasar Pembelajaran Perusahaan. Yayasan Bada. Gajah Mada. Yogyakarta.

Soeharjo, A dan D, Patong. 1973. Sendi-Sendi Pokok Ilmu Usahatani. Departmen Ilmu - Ilmu Sosial Ekonomi Pertanian. Fakulltas Pertanan. IPB. Bogor.

Soehoroe, T.1994. Matematika Ekonomi. Lembaga Penerbit Fakultas Ekonomi Universitas Indonesia. Jakarta.

Soekartawi. 2006. Analisis usahatani .Universitas Indonesia UI-Press. Jakarta Sudjana. 2005. Metode Statistika. Tarsito. Bandung.

Sukirno, S. 2002. Teori Mikro Ekonomi. Rajawali Press. Jakarta.

Suratiyah. 2006. Ilmu Usahatani. Penebar Swadaya. Jakarta.

Analisis Produksi dan Pendapatan Petani Padi Sawah yang Menggunakan Pupuk Hayati Cair di Desa Balang Cut Kecamatan Suka Makmur Kabupaten Aceh Besar. (Syukran, Ismayani, 277 Fajri Jakfar)

Jurnal Ilmiah Mahasiswa Pertanian Unsyiah, Vol. 2, No. 4, November 2017: 271-277 